\title{
Scaling giant kelp field measurements to regional scales using satellite observations
}

\author{
Kyle C. Cavanaugh ${ }^{1, *}$, David A. Siegel ${ }^{1,2}$, Brian P. Kinlan ${ }^{3}$, Daniel C. Reed \\ ${ }^{1}$ Institute for Computational Earth System Science, ${ }^{2}$ Department of Geography, and ${ }^{3}$ Marine Science Institute, \\ University of California, Santa Barbara, Santa Barbara, California 93106-3060, USA
}

\begin{abstract}
Little is known about the local to regional scale variability in biomass and productivity of many subtidal ecosystems, as appropriate field surveys are both time and labor intensive. Here, we combined high-resolution satellite imagery with aerial photos and diver sampling to assess changes in giant kelp Macrocystis pyrifera canopy cover and biomass along a $\sim 60 \mathrm{~km}$ stretch of coastline in the Santa Barbara Channel, California, USA. Our objectives were to (1) develop new methods for estimating giant kelp canopy cover and biomass using satellite imagery, and (2) assess temporal changes in kelp forest biomass across multiple spatial scales. Results of the satellite kelp cover classification compared very favorably with near-coincident high-resolution aerial camera surveys $\left(\mathrm{r}^{2}=\right.$ 0.90). Monthly diver observations of biomass for fixed plots at 3 kelp forest sites were strongly correlated with satellite determinations of normalized difference vegetation index (NDVI) signals $\left(r^{2}=0.77\right)$. This allowed us to examine variation in giant kelp biomass across multiple spatial scales (pixel, plot, site, and region). The relationship between plot scale $(40 \mathrm{~m})$ changes in biomass and remote assessments of site scale $(\sim 1 \mathrm{~km})$ changes varied among sites and depended on the relative location of the plot and the size of the kelp forest at each site. Changes in biomass among sites were well correlated with each other and with the aggregated regional $(\sim 60 \mathrm{~km})$ total. Linking field measurements of giant kelp biomass made on a plot scale with regional estimates made by satellite facilitates an understanding of the regional patterns and drivers of biomass and primary production of giant kelp forest ecosystems.
\end{abstract}

KEY WORDS: Scaling $\cdot$ Remote sensing $\cdot$ Spatial and temporal variability $\cdot$ Giant kelp $\cdot$ Satellite data

\section{INTRODUCTION}

Over the past few decades, the issue of scale has been brought to the forefront of ecology with respect to the processes that shape ecosystems (e.g. Levin 1992, Schneider 2001). While it has become accepted that there is no single optimal spatial or temporal scale at which ecological processes should be described (Levin 1992, 2000, Edwards 2004), most ecological studies have assessed variability over small areas and/or short periods of time due to practical limitations (e.g. Foster 1990, Carpenter 1998). This is especially true in subtidal marine habitats, where spatial sampling typically requires timeand labor-intensive field surveys. However, patterns observed at small scales are often very different than those at larger scales, and locally measured variables often cannot be directly scaled up to larger areas (Schneider 2001). Studies that are designed specifically to sample at multiple spatial and temporal scales can provide valuable insight into how variability is distributed across space and time (e.g. Fowler-Walker \& Connell 2002, Edwards 2004, Edwards \& Estes 2006). Nevertheless, there are still practical limits to the amount of spatial and temporal coverage that can be obtained, and characterizing variability over a broad range of scales is often impractical using classical field sampling techniques. However, insufficient sampling coverage can cause small-scale variations to overwhelm larger-scale patterns of species distributions and dynamics (e.g. Fowler-Walker \& Connell 2002). 
High-resolution remote sensing observations have the potential to monitor patterns and processes of selected ecosystem characteristics across multiple spatial and temporal scales. These techniques have been used for decades to make regional observations of coastal marine ecosystems (Tucker 1979, Jensen et al. 1980, Deysher 1993). Unfortunately, the temporal coverage of these past studies has been relatively limited, largely due to the previously high cost and limited availability of remote sensing data. This limitation has been greatly reduced as recent growth in the commercial satellite industry combined with the release of free imagery from government operated sensors has resulted in the availability of long-term regional and global datasets with high spatial and temporal resolution. These observations can be used to describe the space/time dynamics of coastal ecosystems if methodologies can be developed to extract ecologically meaningful information. However, remote sensing cannot take the place of detailed plot scale in situ observations, which are necessary to convert remote sensing measurements of reflectance into ecologically meaningful data such as leaf area index, carbon biomass, and primary productivity. Ideally, remote sensing and ground sampling should combine synergistically to make progress for both approaches: detailed field sampling increases the ecological uses of remote sensing observations, and remote sensing observations scale up results from local in situ measurements and experiments.

The extensive forests of the giant kelp Macrocystis pyrifera along the California coast provide an ideal system to demonstrate the value of combining remote sensing with field observations. M. pyrifera forms a dense surface canopy that makes it amenable to aerial mapping and remote assessment. Jensen et al. (1980), Augenstein et al. (1991), and Deysher (1993) all found that multispectral satellite data with 20 to $30 \mathrm{~m}$ resolution could be used to map the distribution of large (>10 ha) giant kelp forests in Southern California, USA. However, these studies were both spatially and temporally limited; in each case, no more than 4 dates were analyzed for less than $20 \mathrm{~km}$ of coastline. Further, previous remote studies of $M$. pyrifera only mapped the extent of kelp canopy. While Stekoll et al. (2006) made progress estimating biomass of 2 other species of floating kelps in Alaska (Nereocystis luetkeana and Alaria fistulosa) from high-resolution aerial imagery, satellite imagery has not yet been used to measure M. pyrifera biomass. Species-specific differences in canopy structure and susceptibility to submergence from tides and currents as well as differences between aerial versus satellite imagery require that new methods be developed for satellite mapping of $M$. pyrifera biomass.
Macrocystis pyrifera is of high ecological and economical importance as it provides both food and 3dimensional habitat structure for a diverse array of biologically and commercially important species of algae, invertebrates, fish, and marine mammals (Foster \& Schiel 1985, Steneck et al. 2002, Graham et al. 2007). $M$. pyrifera may also play an important role in regional marine carbon cycles, as kelp forests rank among the most productive ecosystems in the world (Mann 1973, Reed \& Brzezinski 2009). A result of this high productivity is that kelp forests export large quantities of organic matter to adjacent littoral (Polis \& Hurd 1996, Dugan et al. 2003) and continental shelf (Harrold et al. 1998, Vetter \& Dayton 1999) ecosystems. A critical first step in quantifying spatial and temporal patterns in the sources and fate of this productivity involves obtaining comprehensive estimates of the biomass of giant kelp populations.

Our research demonstrates a new application of satellite imagery for making large-scale assessments of giant kelp forests. This paper has the dual aim of (1) developing methods to quantify the canopy area and standing biomass of giant kelp from multi-spectral satellite imagery and (2) assessing temporal changes in kelp forest biomass at multiple spatial scales. We approached our first objective by comparing satellite reflectance signals to diver-based measurements of kelp biomass. We then created a nearly bimonthly time series of satellite derived kelp biomass for the mainland coast of the Santa Barbara Channel in Southern California from January 2006 to December 2007. These observations allowed us to characterize the variation in giant kelp biomass across a spectrum of scales within and among kelp forests of varying size. Specifically, we determined the degree to which the dynamics of kelp biomass measured in relatively small plots $(\sim 40 \mathrm{~m})$ by divers represented that of the site (in this study, 'site' is defined as a discrete patch of kelp forest; these are generally $\sim 1 \mathrm{~km}$ in the Santa Barbara Channel) and the degree to which changes in biomass at the site scale were related to that of our study region in the Santa Barbara Channel ( 60 km).

\section{MATERIALS AND METHODS}

Study sites. The Santa Barbara Channel (SBC) is approximately $100 \mathrm{~km}$ long by $40 \mathrm{~km}$ wide and marks the northernmost region of the Southern California Bight (Fig. 1). We focused on a $60 \mathrm{~km}$ stretch of the mainland coast of the SBC, which is forced by environmental processes operating on a myriad of scales. The nearsurface waters of the SBC typically have their highest nutrient concentrations during the spring and early summer months due to coastal upwelling, while the late 


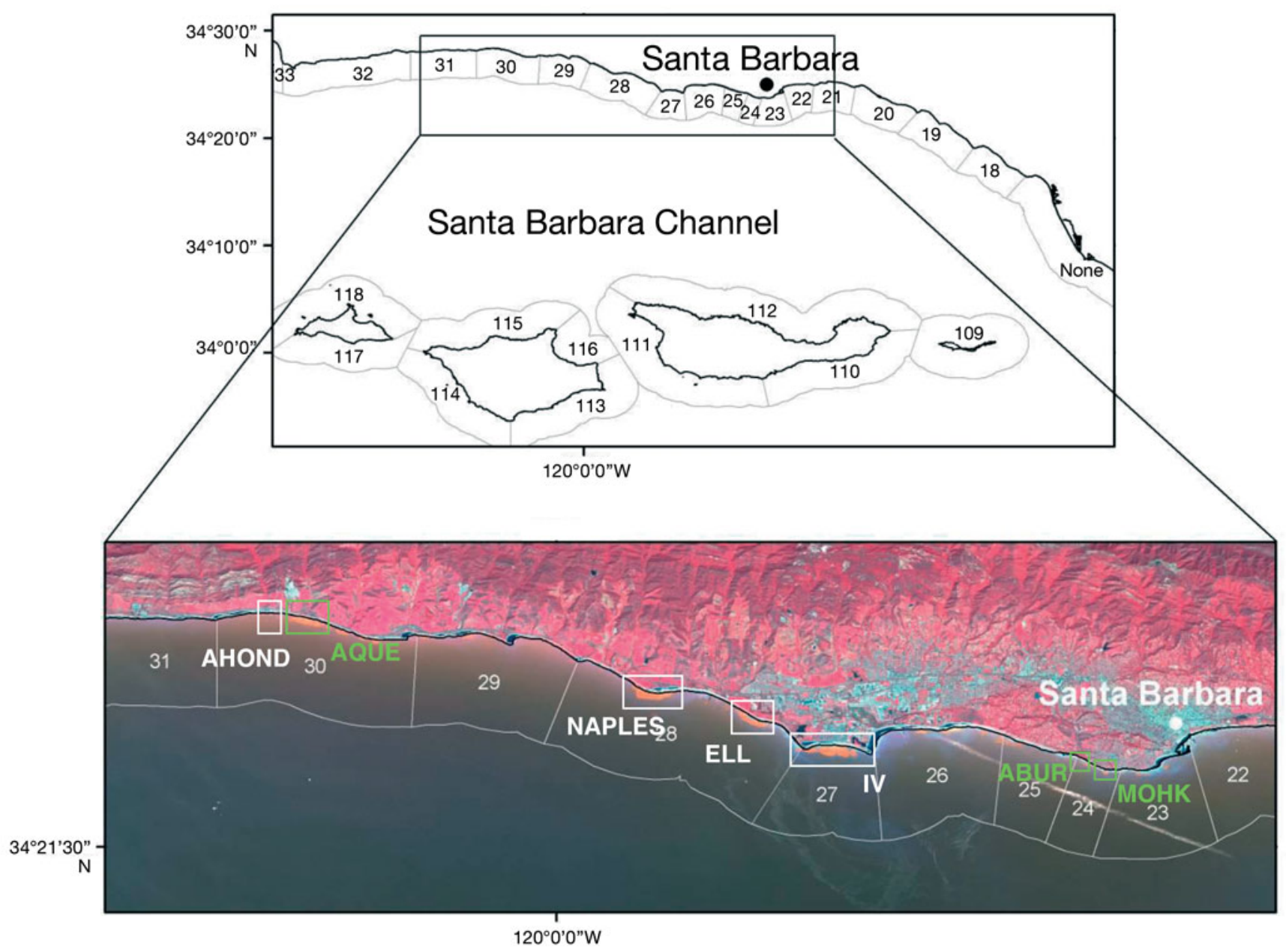

Fig. 1. Study area in the Santa Barbara Channel. Numbered sections of the coastline represent California Department of Fish and Game (CDFG) 'administrative kelp beds.' Study area includes the section of the Santa Barbara mainland displayed on the SPOT satellite image within the inset (CDFG administrative beds 22 to 31). The 7 boxes identify specific forest sites on which later analyses are focused. Site names from west to east: Arroyo Hondo (AHOND), Arroyo Quemado (AQUE), Naples (NAPLES), Ellwood (ELL), Isla Vista (IV), Arroyo Burro (ABUR), and Mohawk (MOHK). Green boxes (AQUE, ABUR, and MOHK): forests where the Santa Barbara Coastal Long Term Ecological Research (SBC LTER) project conducts monthly diver sampling

summer months are marked by vertical stratification, warm surface waters, and low nutrient levels (McPheeShaw et al. 2007). Large swells associated with winter storms are a major source of giant kelp mortality in this area (Reed et al. 2008). On longer time scales, El Niño/Southern Oscillation (ENSO) and Pacific Decadal Oscillation (PDO) events impact kelp population dynamics through the alteration of storm cycles, seawater temperature, nutrient levels, and changes in the distribution and abundance of many species that inhabit kelp forests (Dayton \& Tegner 1989, Reed et al. 2006). The fact that no macrophyte other than Macrocystis pyrifera produces a floating canopy outside of the surf zone in the SBC greatly simplifies the identification of giant kelp from satellite imagery.

Diver surveys. Data on Macrocystis pyrifera biomass were collected monthly by divers in fixed plots at
3 giant kelp forests (Mohawk Reef, 342 23.660' N, $119^{\circ} 43.800^{\prime} \mathrm{W}_{\text {; }}$ Arroyo Burro, 34 ${ }^{\circ} 24.007^{\prime} \mathrm{N}, 119^{\circ} 44.663^{\prime} \mathrm{W}_{\text {; }}$ and Arroyo Quemado, $34^{\circ} 28.127^{\prime}$ N, $120^{\circ} 07.285^{\prime} \mathrm{W}$ ) as part of the Santa Barbara Coastal Long Term Ecological Research (SBC LTER) project (http://sbc.lternet.edu). The data and methods used to calculate giant kelp biomass are described in detail by Rassweiler et al. (2008) and are summarized below.

Giant kelp was sampled in 5 transects $(40 \times 1 \mathrm{~m})$ within $40 \times 40 \mathrm{~m}$ plots at Arroyo Quemado and Mohawk, and in 3 transects totaling $480 \mathrm{~m}^{2}$ within a $1300 \mathrm{~m}^{2}$ plot at Arroyo Burro. All Macrocystis pyrifera plants $>1 \mathrm{~m}$ tall in each transect were counted and measured on each sampling date to determine the densities of plants and fronds at each site. To estimate the standing biomass of $M$. pyrifera, we characterized each plant as consisting of 3 distinct sections: (1) the 
'subsurface' section consisted of fronds that did not reach the surface, (2) the 'water column' section was the subsurface portion of fronds that reached the surface, and (3) the 'canopy' section was the portion of the fronds at the sea surface. For each plant sampled, we counted the number of fronds $1 \mathrm{~m}$ above the holdfast $\left(N_{1 \mathrm{~m}}\right)$ and the number of fronds at the surface $\left(N_{\text {surface }}\right)$, and we measured the water depth at the top of the holdfast $(D)$ and the length of the canopy portion of the longest frond (MAX). The determination of whether fronds reached the surface was based on their length and the depth of the water column (relative to mean low low water, MLLW) rather than on their presence at the surface at the time of sampling, which can be affected by tides and currents. We used these measurements to calculate the combined length of all fronds in each plant section according to the following equations:

Subsurface length $=\left(N_{1 \mathrm{~m}}-N_{\text {surface }}\right)[1+1 / 2(D-1)](1)$

$$
\begin{aligned}
& \text { Water column length }=\left(N_{\text {surface }}\right)(D) \\
& \text { Canopy length }=\left(N_{\text {surface }}\right)(1 / 2 \mathrm{MAX})
\end{aligned}
$$

The lengths of the 3 plant sections were summed to obtain the total length of each plant.

We tested the accuracy of Eqs. (1), (2), and (3) in estimating the total frond length by comparing estimates of length obtained using these equations to actual lengths of adult Macrocystis pyrifera collected monthly from each of the 3 sites during the period June 2002 to June 2003 ( $\mathrm{n}=55$ plants). We measured the length of all fronds on each plant collected from the field and compared the sum of these lengths to the total frond length obtained by summing the values given by Eqs. (1), (2), and (3). Total frond length estimated using Eqs. (1), (2), and (3) was an excellent predictor of actual total frond length $\left(\mathrm{r}^{2}=0.993\right.$, slope $\left.=1.02\right)$

Total length was converted into total mass using relationships generated from length and weight measurements of the 55 adult Macrocystis pyrifera collected from the field (the ratios of frond wet mass [kg] to frond length [m] were $0.117,0.105$, and 0.259 for the subsurface, water column, and canopy sections, respectively). The wet mass of each plant was converted to dry mass based on the average moisture content of blades collected haphazardly from 10 to 15 plants at each site during each monthly survey. Data on plant mass were used to calculate site-specific values for M. pyrifera biomass in units of dry $\mathrm{kg} \mathrm{m}^{-2}$ for each monthly sample period.

High-resolution satellite imagery. The Satellite Pour l'Observation de la Terre (SPOT) 5 multispectral sensor provides $10 \mathrm{~m}$ spatial resolution imagery with 4 spectral bands: green (500-590 nm), red (610$680 \mathrm{~nm})$, near-infrared (790-890 nm), and mid- infrared (1580-1730 nm) (SPOT Image Corporation; Fig. 2). We acquired 13 SPOT 5 (hereafter denoted SPOT) scenes over the Santa Barbara coast between October 2004 and December 2007. The time series includes 3 images from 2004 (dates in mm/dd: 10/24, 11/29, 12/25), 6 from 2006 (02/09, 04/13, 06/04, 08/15, 11/01, 12/23), and 4 images from 2007 (03/22, 04/12, 09/09, 12/22). Each SPOT scene covered an area approximately $60 \times 60 \mathrm{~km}$, incorporating the Arroyo Burro and Mohawk kelp forests. The Arroyo Quemado forest was sampled in all of the above images except $11 / 2004$ and $12 / 2004$; the footprints of these 2 scenes were different from the rest of the images and did not contain Arroyo Quemado.

Kelp reflectance. The spectral signature of Macrosystis pyrifera has characteristics similar to terrestrial vegetation including a chlorophyll absorption feature at $680 \mathrm{~nm}$ and high near-infrared reflectance (Jensen et al. 1980, Augenstein et al. 1991; Fig. 2). The relatively high near-infrared reflectance signal is useful for differentiating kelp because water absorbs almost all incoming near-infrared energy. This method was only useful for analyzing signals from the surface canopy portions of giant kelp (0 to $1 \mathrm{~m}$ depth). Young fronds that have not yet reached the surface are not detected by this method, and processes that submerge surface fronds, such as large tides or strong currents, can have an effect on how much canopy is visible to the sensor (Britton-Simmons et al. 2008).

We examined the relationship between canopy and total forest biomass to assess the feasibility of inferring giant kelp biomass from remote sensing imagery. On

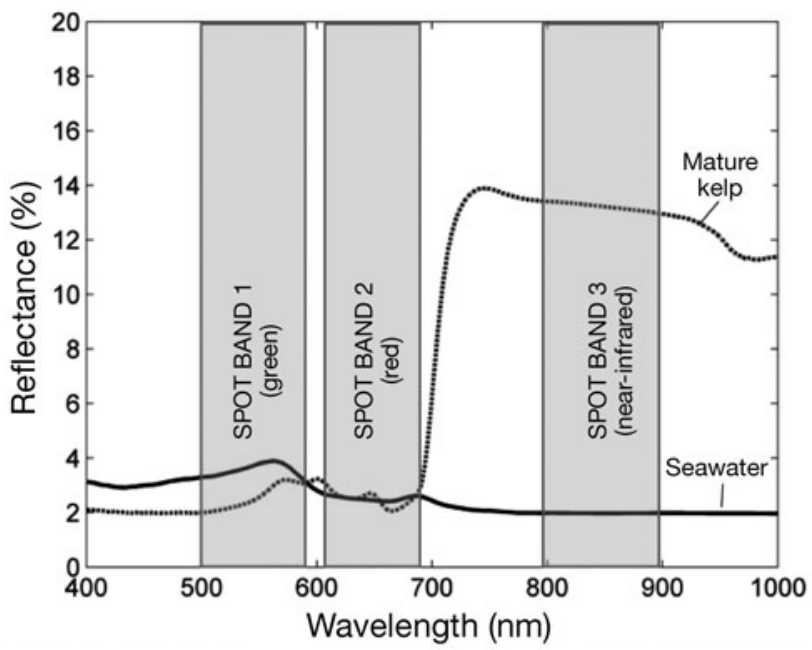

Fig. 2. Visible and near-infrared spectral reflectance signature of giant kelp compared to seawater. Satellite Pour l'Observation de la Terre (SPOT) 5 spectral bands are overlain on the plot (kelp reflectance spectra from R. Zimmermann unpubl. data and water reflectance from Clark et al. 2003. SPOT 5 bandwidths from SPOT Image) 
average, the surface canopy accounted for $35 \%$ of the total forest biomass, and canopy biomass was highly correlated with the total biomass $\left(\mathrm{r}^{2}=0.92\right.$; SBC LTER unpubl. data). This indicates that satellite estimates of surface canopy biomass could serve as a useful measure of total kelp biomass.

Giant kelp canopy delineation. Geometric corrections were made to the SPOT images using rectified $1 \mathrm{~m}$ resolution US Geological Survey (USGS) orthophotos (http://eros.usgs.gov/). Easily identifiable ground control points (e.g. road intersections, piers) were selected on the SPOT image and matched to the USGS orthophoto, and then the image was orthorectified using ENVI software (ITT Visual Information Solutions) based on a first-order polynomial transformation and radiometrically resampled using the nearest neighbor technique. SPOT satellite images were radiometrically and atmospherically corrected following the method of Chavez (1988, 1989, 1996). This method, called dark object subtraction, assumes that there are 'dark' pixels in the image where the measured radiance is dominated by the path radiance. The measured radiance at these 'dark' pixels (cf. pixels from the open ocean) were subtracted from each pixel in the image to account for atmospheric reflectance. The kelp canopy was clearly visible on the resulting atmospherically corrected image (Fig. 3B). Land and cloud areas were then masked out manually.

A principal component (PC) rotation was performed on the image bands using observations between the 0 and $60 \mathrm{~m}$ isobaths, which includes all known habitat for giant kelp in the SBC (35 $\mathrm{m}$ is deepest known depth of Macrocystis pyrifera occurrence in this region). PC analysis takes multiple variables (in this case the variables are each of the 4 SPOT bands) and trans- forms them into uncorrelated variables. Here, each PC represents a combination of SPOT bands; the first PC accounts for as much of the total variance as possible, and each successive PC accounts for as much of the remaining variance as possible. We performed separate $\mathrm{PC}$ rotations for each image, which allowed us to determine how much the band combination for each PC varied from scene to scene. The first PC band explained $95.6 \%$ of the variance on average, and the loadings showed positive contributions from all 3 spectral bands (Table 1). This was interpreted as representing subscene variations in atmospheric conditions, suspended particles, whitecaps, and waves, and other features that increase or decrease reflectance across all bands. The second PC band showed spectral patterns inversely consistent with reflectance signals expected from floating canopy vegetation: positive green and red band reflectance and negative nearinfrared reflectance (compare Table 1 statistics with Fig. 2). The distribution of the second PC band was used to assess kelp-covered pixels (Fig. 3C). The loadings and variance explained by each PC band remained consistent across the time series of satellite imagery, indicating that PC Band 2 was consistently identifying kelp (see standard deviations in Table 1).

Table 1. Statistics from the principal component (PC) rotations performed on SPOT 5 imagery. Rows give the mean $( \pm \mathrm{SD})$ variance explained (eigenvalues) and loadings of the SPOT 5 bands (green, red, near-infrared [NIR]) for each $\mathrm{PC}$ band

\begin{tabular}{|lrrr|}
\hline & PC Band 1 & PC Band 2 & PC Band 3 \\
\hline Variance explained & $0.954(0.025)$ & $0.040(0.022)$ & $0.006(0.003)$ \\
Green band loading & $0.588(0.056)$ & $0.635(0.040)$ & $-0.489(0.091)$ \\
Red band loading & $0.539(0.023)$ & $0.135(0.145)$ & $0.819(0.025)$ \\
NIR band loading & $0.598(0.053)$ & $-0.747(0.030)$ & $-0.269(0.099)$ \\
Interpretation & Clouds, haze, & Kelp canopy & No signal \\
& whitewater & & \\
\hline
\end{tabular}

A

B

C
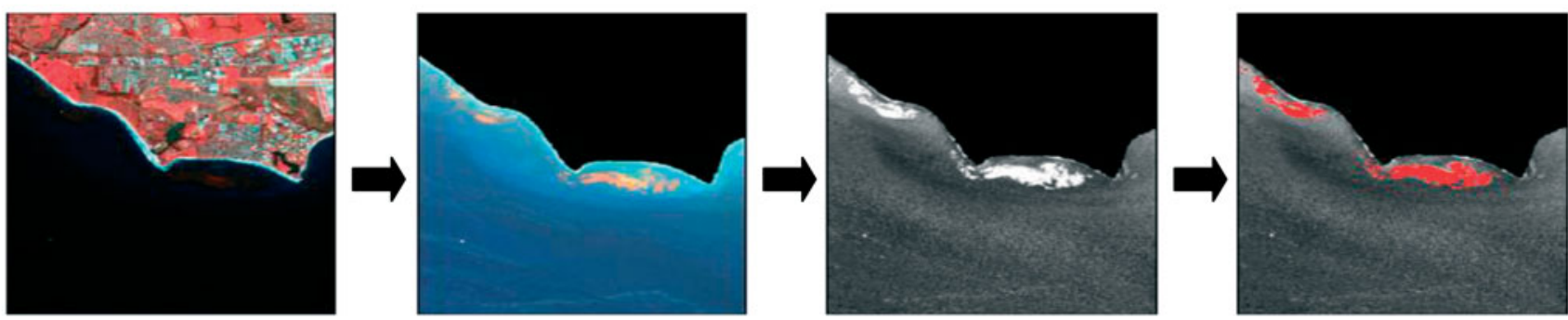

Fig. 3. Steps in the procedure for canopy cover delineation from SPOT 5 imagery. (A) False-color SPOT image after geometric and atmospheric corrections have been performed. (B) Resampled image after land and cloud areas have been masked out. (C) Principal component (PC) Band 2 (see Table 1 for band loadings). Kelp is easily differentiated in this image because the spectral signature of kelp closely matches the second mode of variability of the PC rotation. (D) PC Band 2 after the threshold, manual edits, and winnowing filter have been applied. Pixels identified as giant kelp are displayed in red 
To determine a threshold for kelp-covered pixels, we established a noise level based on offshore water pixels with depths between 35 and $60 \mathrm{~m}$ (outside of the depth range of kelp). We selected the 99.98 percentile value from the histogram of the pixels between 35 and $60 \mathrm{~m}$ and used it as the threshold for kelp-covered pixels. Choosing the 99.98 percentile rather than the absolute maximum ensured there were at least 250 pixels above the threshold in the offshore water mask to account for outliers (e.g. corrupted pixels, cloudcovered pixels, floating kelp wrack). When the threshold was applied to the pixels between 0 and $35 \mathrm{~m}$, all kelp-covered pixels were included. Mistakenly identified pixels were removed manually and by using a winnowing filter that eliminated isolated pixels (Fig. 3D).

We compared our SPOT kelp canopy maps to $2 \mathrm{~m}$ resolution aerial kelp surveys made by the California Department of Fish and Game (CDFG) in the fall of 2004 and 2006. The CDFG classified kelp canopy from aerial photos with an unsupervised classification algorithm, and placed shapefiles outlining canopy extent in a publicly available GIS database (Veisze et al. 2001). For resource management purposes, the CDFG has divided the coast of California into 2 to $20 \mathrm{~km}$ sections termed 'administrative kelp beds' (see Fig. 1), and the SPOT/CDFG comparisons were made on an administrative bed basis. CDFG aerial surveys were done between September and November of 2004 and 2006, but the exact survey dates for each subsection of the surveys are not conveyed with the data. Thus it is possible that a time lag of up to 3 mo occurred between the SPOT and CDFG surveys.

Satellite estimation of giant kelp biomass. To estimate giant kelp biomass from SPOT imagery, we employed a common terrestrial vegetation index known as the normalized difference vegetation index (NDVI; for terrestrial applications see Tucker 1979, Tucker et al. 1985, Paruelo et al. 1997, Ricotta et al. 1999). The NDVI represents the normalized difference between near-infrared and visible reflectance and is commonly expressed as

$$
\mathrm{NDVI}=\frac{\rho_{\text {nir }}-\rho_{\text {red }}}{\rho_{\text {nir }}+\rho_{\text {red }}}
$$

where $\rho_{\text {nir }}$ is the reflectance in the near-infrared spectrum and $\rho_{\text {red }}$ is the reflectance in the red spectrum. Terrestrial vegetation typically has higher reflectance in the near-infrared region than in the visible and therefore the NDVI signal follows increases in plant biomass. While NDVI is commonly used for estimating terrestrial biomass, it has rarely been applied to marine vegetation since near-infrared energy cannot significantly penetrate more than $1 \mathrm{~m}$ into the water column (for exceptions see Stekoll et al. 2006, Su et al. 2006,
Yang \& Yang 2009). However, since giant kelp has a spectral signature similar to terrestrial vegetation (including low red reflectance and high near-infrared reflectance; Fig. 2) and forms a floating canopy, the NDVI of an area of kelp canopy should be related to canopy biomass.

We compared SPOT-derived NDVI determinations to diver measurements of giant kelp frond density and biomass in the SBC LTER plots at Arroyo Quemado, Arroyo Burro, and Mohawk in order to develop a parameterization for kelp biomass. Diver-sampled plots were digitized onto a GIS layer and overlaid onto the NDVI image, and average NDVI values for all pixels intersecting the plots were calculated. The diver plots at Arroyo Quemado and Mohawk were enclosed by 16 pixels in a SPOT 5 image $\left(1600 \mathrm{~m}^{2}\right)$ while the plot at Arroyo Burro was enclosed by 13 SPOT 5 pixels $\left(1300 \mathrm{~m}^{2}\right)$. The area for each NDVI determination was somewhat larger than the area sampled by divers. This difference in spatial scale likely contributed uncertainty to the NDVI/biomass relationship. We matched each image with the diver survey closest in time; generally the 2 were separated by less than $1 \mathrm{wk}$, although in a couple of cases there were time lags of 2 to $3 \mathrm{wk}$. Again these time lags introduced uncertainty to the NDVI/biomass relationship. A total of 13 different dates for Mohawk and Arroyo Burro and 11 dates for Arroyo Quemado were used in our analyses.

To validate regional biomass estimates made from the relationship between the satellite and field determinations of biomass (a description of this relationship follows) we compared SPOT estimates of Macrocystis pyrifera biomass to those obtained from aerial surveys conducted by the kelp-harvesting company ISP Alginates. The aerial surveys were done from a small plane by trained observers and consisted of visual estimates of the harvestable surface biomass ( 0 to $1 \mathrm{~m}$ depth) of each CDFG administrative bed (Reed et al. 2006). Aerial surveys were flown approximately bimonthly from 1968 to 2005 and in February 2006 and April 2007. For this study, we used data from aerial surveys of the SBC done between 2004 and 2007.

Strong currents and highly variable surface tides can affect how much kelp canopy is visible on the surface of the water and therefore its remote quantification (e.g. Stekoll et al. 2006, Britton-Simmons et al. 2008). High tides can submerge the canopy while high currents can drag fronds below the surface of the water, and a partially submerged canopy will have lower NDVI values than expected. However, tides and currents did not affect the estimates of biomass obtained in the diver surveys (see 'Diver surveys' above). The effects of tides and currents on the relationship between NDVI and kelp biomass were assessed by measuring currents and tidal heights at the time of satellite 
imagery acquisition and determining if these data improved the NDVI-biomass fit. Current measurements were collected from bottom-mounted acoustic Doppler current profiler (ADCP) systems deployed shoreward of the Arroyo Quemado, Arroyo Burro, and Mohawk kelp forests by the SBC LTER. The magnitude of the current vector was averaged over the top $3 \mathrm{~m}$ of the water column; direction was not taken into account. Astronomical tidal levels were determined from the tide database WTides (www.wtides.com).

Geostatistical analysis. Satellite estimations of biomass allowed us to measure large-scale changes in kelp biomass and compare these to small-scale, diver-measured dynamics. We compared diver measurements of biomass in the plots at Arroyo Quemado, Mohawk, and Arroyo Burro to estimates of the total biomass at each site calculated from SPOT imagery (green boxes in Fig. 1).
The sites were defined as discrete patches of kelp canopy and delineated on SPOT images by divers with experience in sampling at these locations. The white boxes in Fig. 4A outline the area over which total biomass at each site was calculated while the small green lines show the SBC LTER plots. This comparison provides insight into how well the plot-scale diver measurements of biomass characterized the dynamics of the entire kelp forest surrounding those plots.

The high resolution of the SPOT images allowed us to simulate how the correlation between plot- and sitescale dynamics changes as a function of plot location within the kelp forest. We investigated the extent to which changes in biomass of different parts of the forest (i.e. center, shoreward edge, seaward edge) were correlated with changes in the biomass of the entire kelp forest by calculating the correlations between the bio-
A

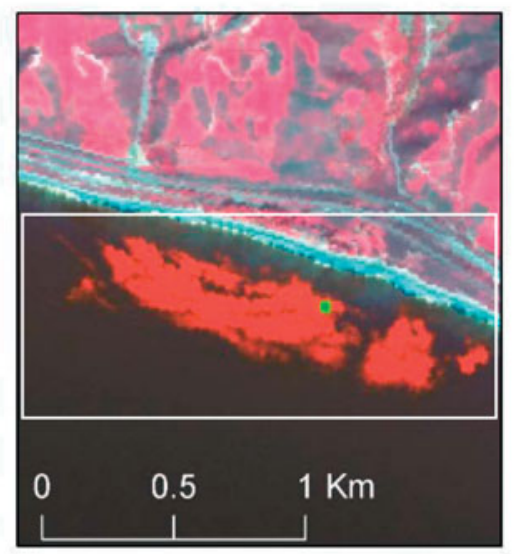

Mohawk

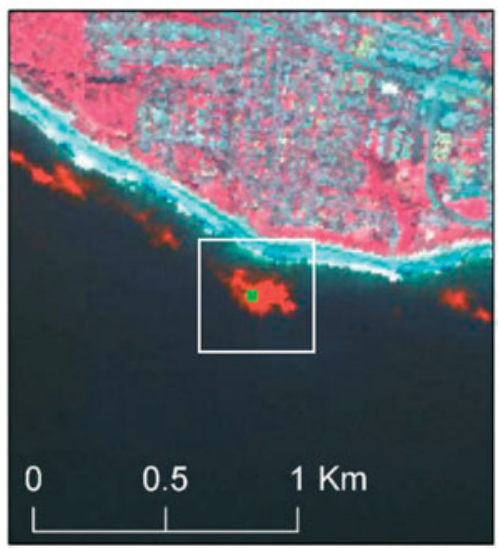

Arroyo Burro

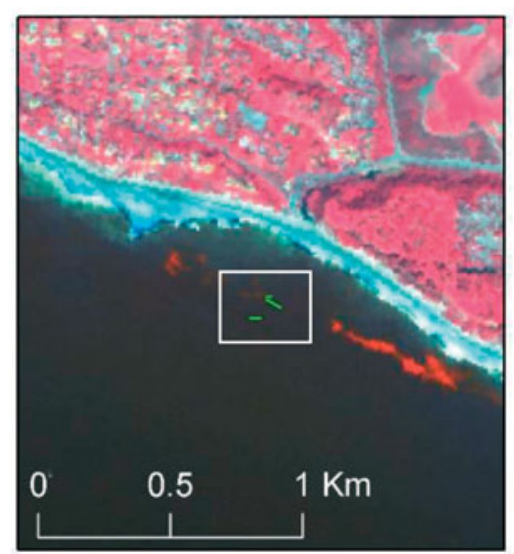

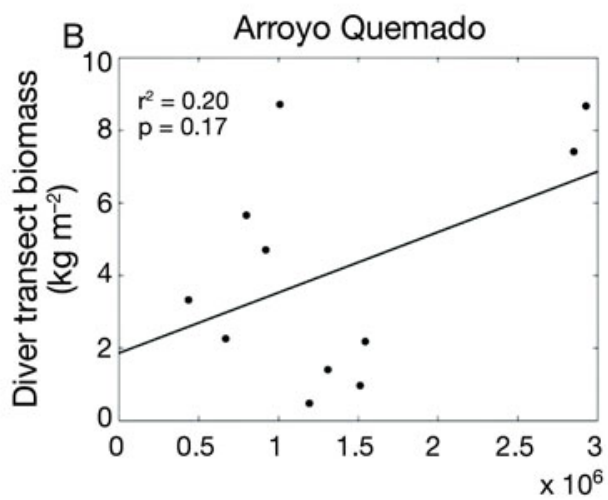
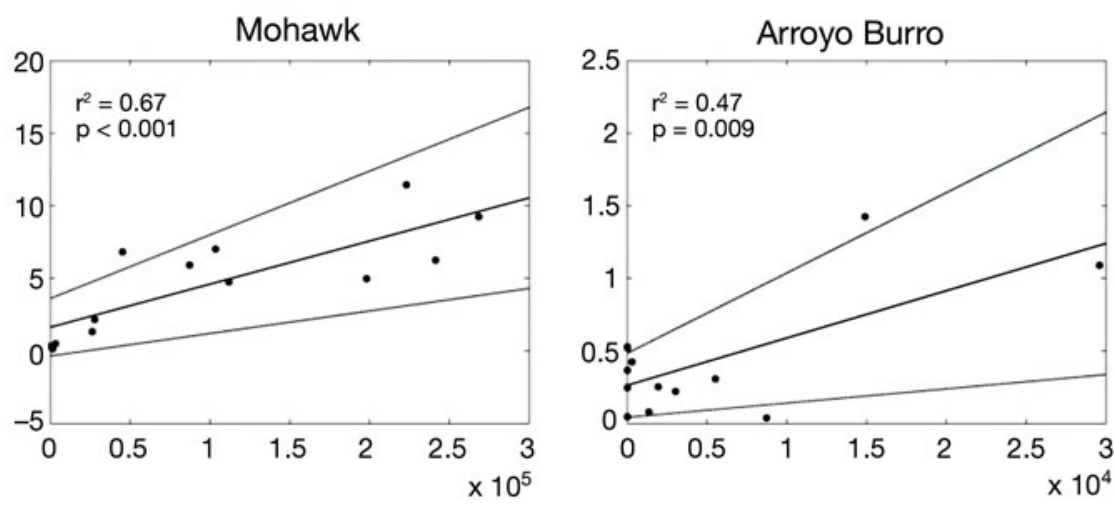

Total site biomass $(\mathrm{kg})$

Fig. 4. (A) False-color images of the Arroyo Quemado, Mohawk, and Arroyo Burro kelp forests. Kelp canopy is red/orange in the image because the near-infrared (NIR) signal is displayed in red. White boxes represent the boundary for which total site biomass was calculated; small green lines represent the SBC LTER diver transects at each site. (B) Comparison of diver collected plot-scale measurements of biomass $\mathrm{m}^{-2}$ with site-scale estimates of biomass calculated from SPOT imagery. Site biomass ( $x$-axis) was summed over area enclosed in the white boxes in (A). Each point represents an image date and corresponding diver sampling date ( $\mathrm{n}=11$ to 13 dates between October 2004 and December 2007). Solid line represents regression line; dotted lines give $95 \%$ confidence intervals for significant relationships. Note different scales for $x$ - and $y$-axes for each site 
mass of individual pixels and that of the entire forest (using the non-parametric Spearman correlation coefficient) for each of the pixels of the 4 largest kelp forests identified by the green and white boxes in Fig. 1.

Spatial autocorrelation determinations provide a general answer to the question of how far plot scale data can be extrapolated. We examined this question using semivariogram analyses. Semivariance is half the measured variance between all pairs of pixels separated by increasing lag distances $(h)$ and is used to determine the amount of spatial autocorrelation in a dataset (Deutsch \& Journel 1998). We calculated both alongshore and cross-shore semivariograms for each of the 7 sites in Fig. 1 because kelp forests are generally anisotropic. All 13 image dates were combined to create a single semivariogram for each kelp forest, which we used to represent the average spatial structure of each kelp forest over the time series. The semivariogram parameters were estimated by fitting exponential models to the empirical semivariograms using weighted non-linear least squares minimization.

We increased our spatial scale of interest from within-site scales $(\sim 1 \mathrm{~km})$ to within the $\mathrm{SBC}$ region $(\sim 60 \mathrm{~km})$ to examine the degree of similarity in the dynamics of kelp forests in the SBC during the time period for which we had SPOT imagery (2006-2008). We calculated the Spearman correlation coefficient for each pair of the 7 large kelp forests identified in Fig. 1 and between the biomass of each kelp forest and the total biomass for the entire region.

Finally, we used the coefficient of variation (CV) to examine variability through time at 4 different spatial scales (pixel, plot, site, and region). The pixel scale $(10 \mathrm{~m}) \mathrm{CV}$ was calculated by averaging the temporal CVs of each pixel containing kelp biomass at least twice during the time series. The plot scale $(40 \mathrm{~m}$ corresponding to $4 \times 4$ SPOT pixels) CV represents the average variation of an area the size of the SBC LTER diver plots. The site scale was defined as discrete patches of kelp canopy, which ranged in size from 1500 to $448000 \mathrm{~m}^{2}$ (100 $\mathrm{m}$ to $2.5 \mathrm{~km}$ in alongshore distance). The region was defined as the area covered by a single SPOT image ( $60 \mathrm{~km}$ in the alongshore direction).

\section{RESULTS}

\section{Kelp canopy delineation}

Comparisons of the CDFG aerial surveys and the SPOT satellite surveys were made on an administrative bed basis for a total of 15 administrative beds in 2004 and 8 administrative beds in 2006 (Fig. 5A). The canopy area estimates from the CDFG aerial surveys matched well with the SPOT measurements $\left(\mathrm{r}^{2}=0.90\right.$, $\mathrm{p}<0.001$, slope $=1.2)$ even though the resolution and timing of the 2 surveys were different. This strong relationship provided a good first order validation of the SPOT-derived determinations of kelp canopy area.

\section{Kelp biomass determination}

We found a strong positive and significant linear relationship between NDVI and biomass $\left(\mathrm{r}^{2}=0.77\right.$, p $<<0.001$; Fig. 5B) as well as a weaker but nevertheless significant relationship between NDVI and frond density $\left(r^{2}=0.54, p<<0.001\right.$; Fig. 5 C). We tested for heterogeneity in slopes between sites and did not find that the slopes differed significantly for either relationship (NDVI-biomass: $\mathrm{p}=0.14$; NDVI-frond density: $\mathrm{p}=$ 0.46). In 2003, much of the rocky substrate at Arroyo Burro was covered by a persistent layer of sediment that inhibited kelp recruitment (Reed et al. 2008) and suppressed the development of a surface canopy. The consistently low abundance of kelp at Arroyo Burro resulted in the extremely low NDVI and divermeasured biomass observed at this site throughout the time series (Fig. 4B). A surface canopy was visible in the images of almost all dates at Arroyo Quemado and Mohawk, where kelp was consistently more abundant. Arroyo Quemado and Mohawk had similar average values for biomass (4.04 and $4.44 \mathrm{~kg} \mathrm{~m}^{-2}$, respectively) and NDVI ( 0.30 and 0.27 , respectively).

Currents and tidal fluctuations at the time of imaging were relatively low: mean current speed was only $0.06 \mathrm{~m} \mathrm{~s}^{-1}$ (the maximum speed was $0.18 \mathrm{~m} \mathrm{~s}^{-1}$ ), and tidal excursions ranged from -0.05 to $+1.8 \mathrm{~m}$. A stepwise multiple regression analysis predicting NDVI from diver-measured biomass, currents, and tides did not show improvement over the single regression of NDVI against diver-measured biomass, as biomass was the only term that entered into the multiple regression model. Further, no significant relationship was found between the residuals of the single NDVIbiomass regression and either current speed or tidal level ( $p=0.24$ and 0.11 for current speed and tidal level, respectively). These results suggest that neither currents nor tidal excursions had a first order effect on the satellite determination of kelp biomass.

Estimates of biomass on an administrative bed scale for the coastline between the Mohawk and Arroyo Quemado kelp forests (approximately $60 \mathrm{~km}$ ) were made using the observed relationship between NDVI and biomass (Fig. 5B). Remotely sensed estimates of biomass on the administrative bed scale compared well with visual estimates of biomass from aerial surveys by ISP Alginates $\left(r^{2}=0.73, p<0.001\right)$; however, the satellite estimates were 5 times higher than the visual estimates (regression slope $=5.2$, Fig. 5D). A 

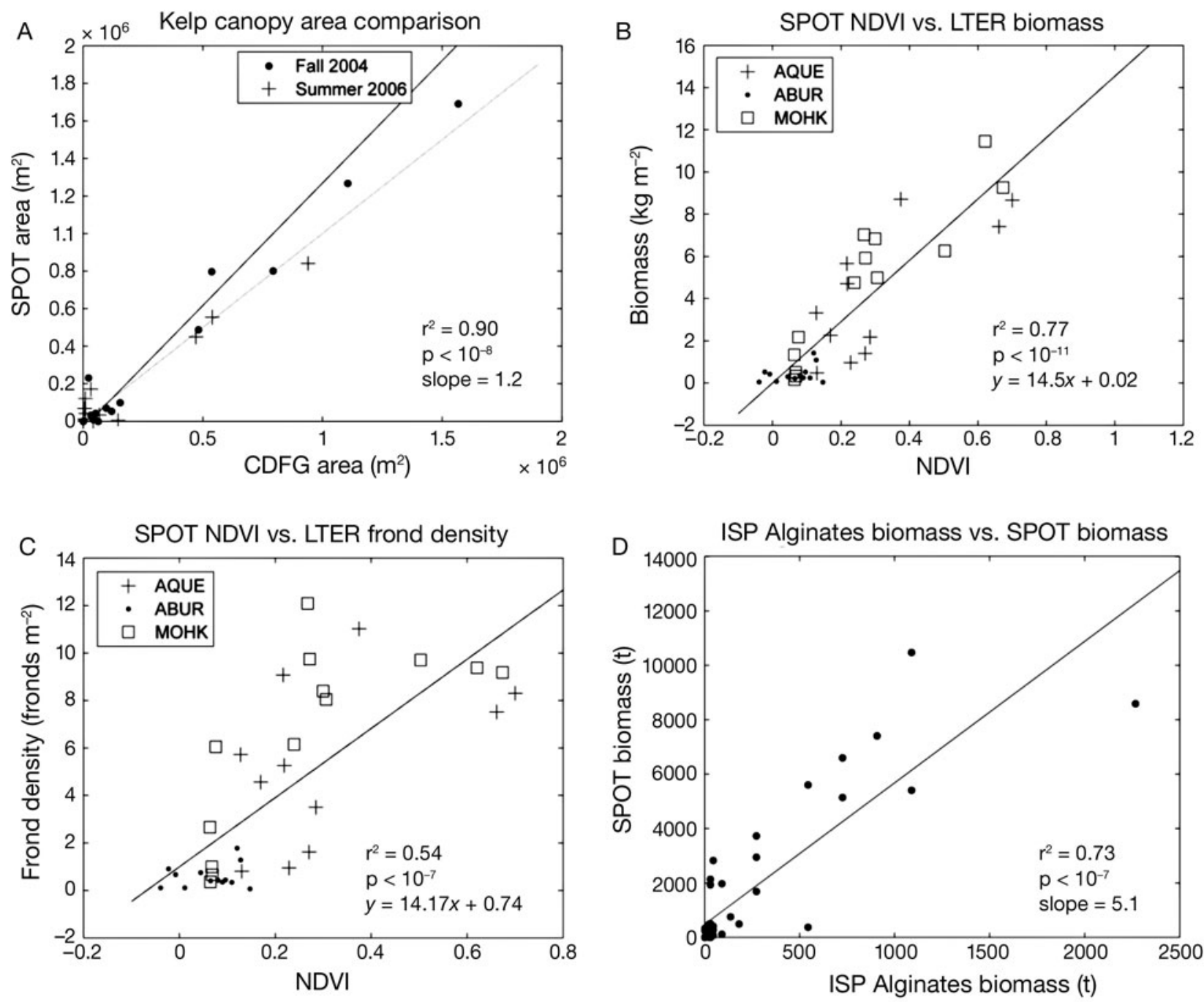

Fig. 5. Validation of satellite canopy and biomass estimates. (A) Comparison between kelp canopy area (by administrative bed) from SPOT and CDFG surveys in summer 2006 and fall $2004(\mathrm{n}=34)$. Solid line is the regression line and dotted line is the 1:1 line. (B) Comparison and linear regression analysis between SPOT normalized difference vegetation index (NDVI) and diver biomass $\left(\mathrm{kg} \mathrm{m}^{-2}\right.$ ) measurements for Arroyo Burro (ABUR), Arroyo Quemado (AQUE), and Mohawk (MOHK) between October 2004 and December 2007 ( $\mathrm{n}=37$ ). (C) Comparison and linear regression analysis between SPOT NDVI and diver frond density (fronds $\mathrm{m}^{-2}$ ) measurements for ABUR, AQUE, and MOHK between October 2004 and December 2007 ( $\mathrm{n}=37$ ). (D) Comparison between ISP Alginates visual canopy biomass estimations and SPOT derived biomass estimations $(\mathrm{n}=44)$. Biomass is given in metric tons and is grouped by administrative bed

likely reason for this difference was that the satellite biomass estimates were based on total biomass, whereas the aerial visual estimates were calibrated to the canopy biomass ( 0 to $1 \mathrm{~m}$ depth) to support harvesting. For our sampling dates, diver surveys showed that the canopy accounted for on average $\sim 30 \%$ of total forest biomass (Rassweiler et al. 2008). When this factor was applied to the SPOT estimates, they corresponded very well with the visual estimates $\left(\mathrm{r}^{2}=0.73, \mathrm{p}<<\right.$ 0.001 , regression slope $=1.4$ ). The agreement between these 2 techniques provides a good independent validation for our satellite estimates of kelp biomass.

\section{Spatial correlation and variability}

We found a significant relationship between the diver-determined plot biomass and the satellite-determined site biomass of giant kelp at Mohawk and Arroyo Burro, but not at Arroyo Quemado, where the kelp forest was substantially larger (Fig. 4B). The average areas for the kelp forests at Arroyo Quemado, Mohawk, and Arroyo Burro were 290 000, 21 000, and $1500 \mathrm{~m}^{2}$, respectively. The mean estimates of giant kelp biomass followed a similar trend (1400000, 100000 , and $5000 \mathrm{~kg}$ for Arroyo Quemado, Mohawk, 
and Arroyo Burro, respectively). These 3 kelp forests exhibited the intuitive result that larger kelp forest changes are more difficult to characterize using smallscale plot measurements.

Examination of spatial and temporal patterns of kelp biomass at the pixel scale in the 4 largest kelp forests in our study area provided insight into the extent to which diver estimates of total forest biomass are influenced by sampling location within the forest (diver plots comprised 16 SPOT 5 pixels). In general, the centers of kelp forests had higher mean biomass and lower temporal variability than the edges, although there was considerable spatial heterogeneity in both quantities (Fig. 6). Spearman-rank correlations between the biomass of a given pixel and the biomass of the forest showed that the high biomass, low variability centers of kelp forests were more highly correlated with the biomass of the entire kelp forest through time than were the edges.

Semivariogram analyses used to assess the spatial structure of individual kelp forests showed that the kelp forests in our study region were anisotropic with larger length scales in the along-shore direction. Fig. 7 \& Table 2 display the proportion of unresolved small-scale variance (i.e. nugget) and length scale of spatial structure (i.e. range) for each kelp forest in the along- and cross-shore directions. Because measurements of biomass will be uncorrelated with each other at distances greater than the range, these analyses provide a measure of how far plot scale observations can be extrapolated. In the alongshore direction, the average nugget and range were 0.13 and $174 \mathrm{~m}$, respectively. Nuggets and ranges generally increased with increasing kelp forest size, indicating that larger forests had a higher amount of small-scale variability than smaller forests, but were spatially autocorrelated at longer distances (Table 2). The larger ranges seen in larger kelp forests were expected as they had the longest alongshore dimensions (Fig. 7). In the cross-shore direction, the average nugget and range were similar to the alongshore direction $(0.2$ and $169 \mathrm{~m}$, respectively). However, the relationships between kelp forest size and both nugget and range were not as strong in the cross-shore direction (Fig. 7). In the SBC, the continental shelf is relatively steep, and giant kelp is restricted to shallow water $(<30 \mathrm{~m})$ within a narrow band of shore (typically $<1 \mathrm{~km}$ wide). There is little variation in bathymetry steepness along the coast, and this is reflected in the uniformity of kelp forest shape and range estimates in the cross-shore direction (Table 2). Differences in canopy area among sites occur as kelp forests grow larger by extending parallel to the coast when conditions are suitable.

Relatively strong regional scale correspondence was found in kelp biomass among most kelp forests and between each forest and the region as a whole (Table 3). All sites experienced a decrease in biomass in January 2007 and subsequent recovery during the following spring and early summer before abruptly declining in October 2007 (Fig. 8). This high degree of intra-annual variability typically reflects wave-driven disturbances associated with winter storms, whose frequency and intensity vary among years (Reed et al. 2008).

The dynamics of kelp biomass varied with the spatial scale at which it was measured (Fig. 9). The greatest temporal variability was observed at fine spatial resolutions (pixel and plot scales), where different parts of kelp forests showed vastly different dynamics (Fig. 6). The low levels of variability observed in the persistent

Table 2. Exponential variogram model parameters fit to empirical semivariograms using weighted non-linear least squares estimation evaluated separately in the alongshore and cross-shore directions. Kelp forests are ordered from smallest to largest in terms of mean area. Site abbreviations as in legend to Fig. 1. Nugget: proportion of unresolved small-scale variance (unitless); sill: normalized fraction of spatially structured variance (unitless); range: length scales of the spatial structure (m)

\begin{tabular}{|lcccccccc|}
\hline \multirow{2}{*}{ Site } & \multirow{2}{*}{$\begin{array}{c}\text { Mean area } \\
\left(\mathrm{m}^{2}\right)\end{array}$} & \multicolumn{3}{c}{ Alongshore } & & \multicolumn{3}{c|}{ Cross-shore } \\
\cline { 5 - 9 } & & Nugget & Sill & Range & & Nugget & Sill & Range \\
AHOND & 7700 & 0.03 & 0.86 & 67.93 & & 0.29 & 0.79 & 104.13 \\
MOHK & 21000 & 0.07 & 0.82 & 107.72 & & 0.16 & 1.63 & 201.86 \\
ELL & 240000 & 0.13 & 0.69 & 116.7 & & 0.19 & 0.81 & 113.94 \\
AQUE & 290000 & 0.21 & 0.72 & 238.9 & & 0.23 & 1.21 & 271.07 \\
NAPLES & 420000 & 0.15 & 0.59 & 159.49 & & 0.13 & 0.79 & 117.52 \\
IV & 500000 & 0.19 & 0.71 & 350.17 & & 0.18 & 0.70 & 204.37 \\
\hline
\end{tabular}

Table 3. Spearman rank correlation of total site biomass between each of the 7 kelp forests outlined with green and white boxes in Fig. 1 and the total regional biomass from January 2006 to January 2008. Bold represents significance at $\mathrm{p}<0.05$. Forests are ordered from smallest to largest in terms of mean biomass. Site abbreviations as in legend to Fig. 1

\begin{tabular}{|lccccccc|}
\hline & AHOND & MOHK & ELL & AQUE & NAPLES & IV & Total \\
\hline ABUR & 0.34 & $\mathbf{0 . 8 1}$ & 0.29 & -0.13 & 0.38 & 0.55 & 0.61 \\
AHOND & - & $\mathbf{0 . 7 3}$ & $\mathbf{0 . 7 7}$ & 0.44 & 0.51 & 0.60 & 0.58 \\
MOHK & & - & 0.58 & 0.12 & 0.52 & $\mathbf{0 . 6 8}$ & $\mathbf{0 . 7 0}$ \\
ELL & & & - & 0.39 & $\mathbf{0 . 8 4}$ & $\mathbf{0 . 6 8}$ & $\mathbf{0 . 7 5}$ \\
AQUE & & & & - & 0.53 & 0.42 & 0.35 \\
NAPLES & & & & & - & $\mathbf{0 . 8 2}$ & $\mathbf{0 . 8 8}$ \\
IV & & & & & & - & $\mathbf{0 . 9 4}$ \\
\hline
\end{tabular}



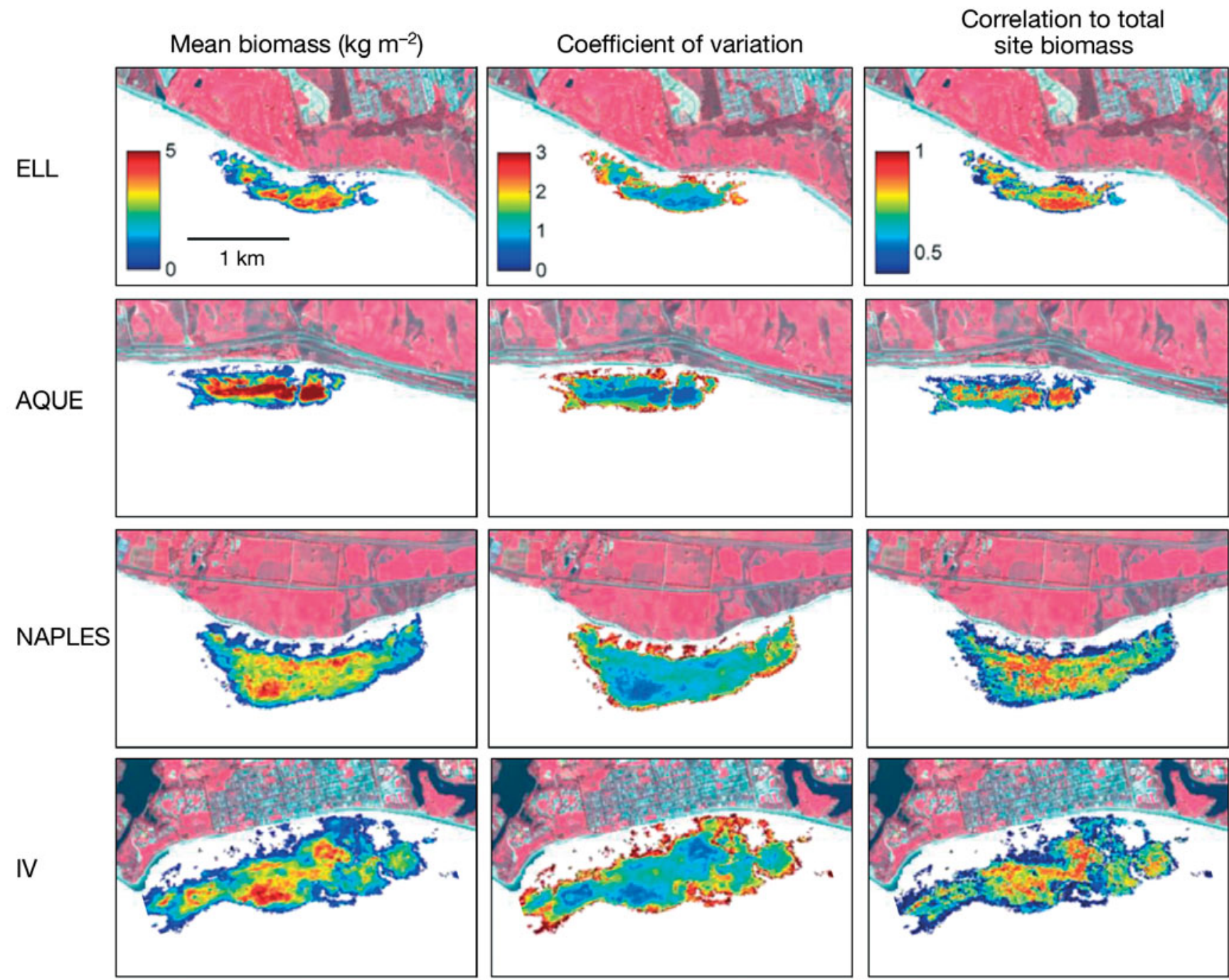

Fig. 6. Mean biomass, coefficient of variation in biomass, and Spearman rank correlation coefficient for the relationship between a given pixel in a kelp forest and total site biomass for ELL, AQUE, NAPELS, and IV. Images from January 2006 to December 2007 are used. See Fig. 1 for site locations. Sites are ordered by increasing size. Each pixel is $10 \times 10 \mathrm{~m}$; each box outlines the same total area $(2.75 \times 1.5 \mathrm{~km})$

centers of individual kelp forests were comparable to those of site and regional scale observations (Fig. 6 compared to Fig. 9). However, the high temporal variability associated with the edges of kelp forests caused the coefficients of variation at pixel and plot scales to be much higher on average than those associated with the site and regional scales (Fig. 9).

\section{DISCUSSION AND CONCLUSIONS}

\section{Satellite kelp canopy cover and biomass estimates}

In situ measurements of giant kelp biomass and productivity require extensive efforts (Rassweiler et al.
2008, Reed et al. 2008). Even indirect estimates of biomass and productivity based on more easily measured variables such as plant or frond density (Reed et al. 2009) necessitate time- and labor-intensive diver surveys, which are inefficient for obtaining region-wide estimates. Aerial and satellite sensors have long been recognized as effective tools for expanding the scale of giant kelp observations (e.g. Jensen et al. 1980); however, until now imagery has not been collected in conjunction with detailed field data on ecologically relevant time scales. Here, we combined detailed field sampling with large-scale remote sensing data and found a significant relationship between the satellitesensed NDVI and diver-measured biomass within the entire water column. This relationship enables accurate estimates of kelp biomass to be made across a 
wide range of spatial scales and thus greatly facilitates studies aimed at exploring the local and regional dynamics of giant kelp, which is a major primary producer in temperate coastal seas throughout the world.

Regional scale measurements of giant kelp biomass can be estimated as the product of surface canopy area and biomass density, which can both be determined from satellite observations. To what extent do changes

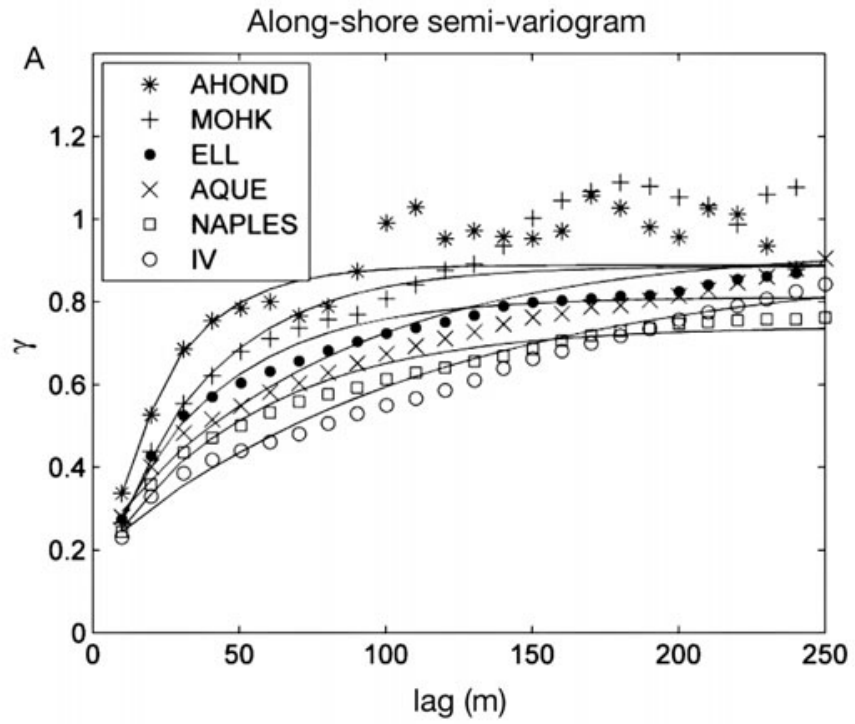

B

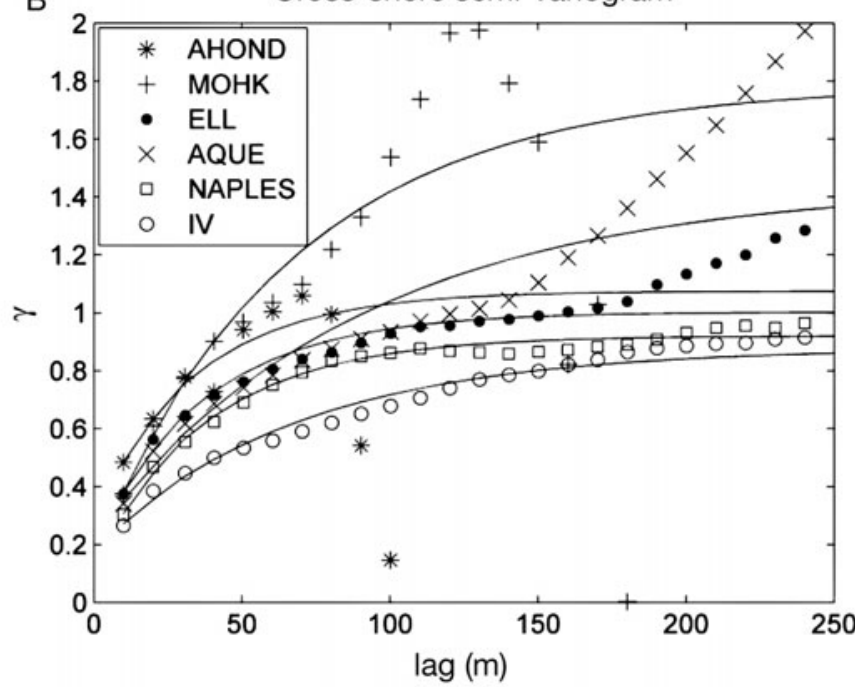

Fig. 7. (A) Alongshore, and (B) cross-shore semivariance of pixel biomass for AHOND, MOHK, ELL, AQUE, NAPLES, and IV. Solid lines represent exponential variogram model fits determined using weighted nonlinear least squares estimation for each site. Exponential variogram model parameter fit values are given in Table 2 . Only pixels of kelp canopy identified by the principal component (PC) process were included in this analysis. ABUR was omitted because it had so few pixels of kelp. Sites are ordered from smallest to largest in terms of total site biomass. Site abbreviations as in Fig. 1

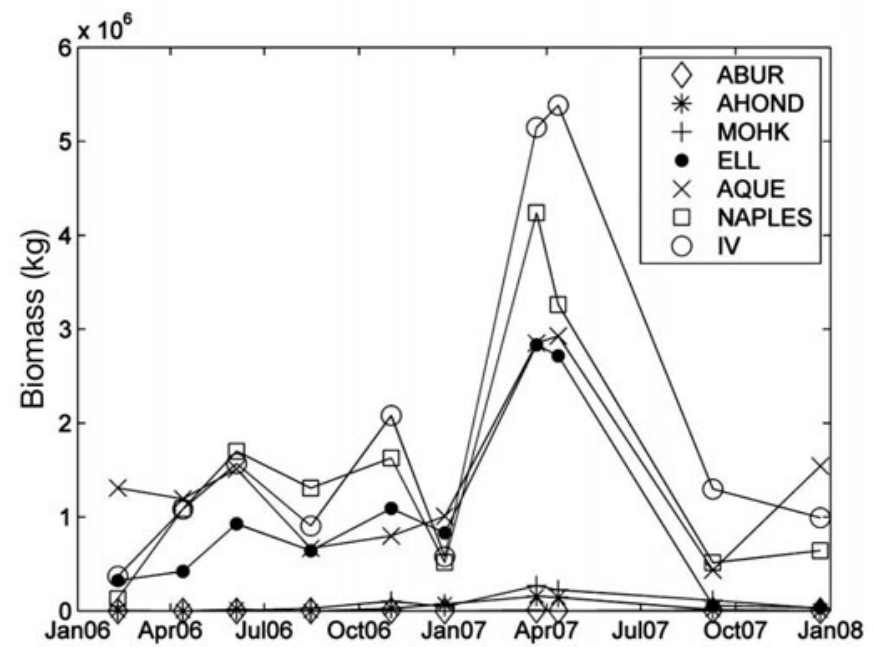

Fig. 8. Time series of site biomass estimated from SPOT imagery at the 7 sites identified in Fig. 1. Biomass was calculated for each pixel classified as kelp and then summed across all pixels for each site. Note the sharp increase in kelp biomass during late winter 2006/early spring 2007

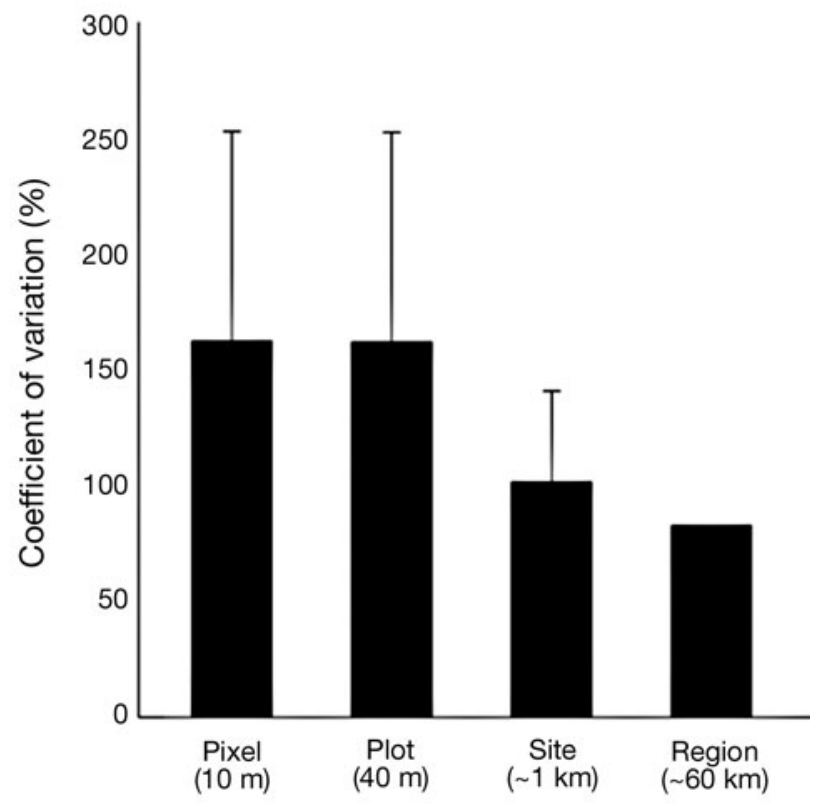

Fig. 9. Temporal coefficient of variation at various scales of observation calculated using imagery from between January 2006 and December 2007 (10 dates). Pixel scale represents the average $\mathrm{CV}$ of all the pixels containing biomass in at least 2 image dates $(\mathrm{N}=110000)$. Plot scale represents the average $\mathrm{CV}$ of 16 SPOT pixels $\left(1600 \mathrm{~m}^{2}\right)$, the minimum number needed to cover the area of a diver plot $(n=7000)$. Site scale represents the biomass of each of the 7 moderate to large kelp forests shown in Fig. $1(\mathrm{n}=7)$. Region scale represents the mainland coast of the Santa Barbara Channel $(\mathrm{n}=1)$. Distances given in parentheses are the approximate alongshore resolution of the observations 
in canopy area versus changes in biomass density control the dynamics of regional kelp biomass? We answered this question by evaluating biomass changes for each administrative bed contained in all images in our time series $(\mathrm{N}=79)$ relative to changes in the canopy area and average biomass density of that administrative bed. Regional biomass was more strongly related to canopy area $\left(F_{1,78}=631, \mathrm{r}^{2}=0.89, \mathrm{p}<<0.001\right)$ than biomass density $\left(F_{1,78}=49, \mathrm{r}^{2}=0.39, \mathrm{p} \ll 0.001\right)$. This is likely due in part to the greater dynamic range of variation in canopy area $(\mathrm{CV}=93 \%)$ compared to biomass density $(\mathrm{CV}=51 \%)$. This finding indicates that canopy area is a good proxy for biomass in giant kelp forests and that satellite-derived data of canopy area can provide a useful means of assessing the regional dynamics of the standing biomass of giant kelp.

Currents and tides have the potential to bias aerial estimates of giant kelp area and biomass. However, we found that currents or tides did not explain any significant additional variation in the relationship between satellite-derived NDVI and diver-measured biomass. This may be partly due to the fact that both currents and tidal excursions were fairly weak during our study. Britton-Simmons et al. (2008) found a significant effect of currents on estimates of forest size of the kelp $\mathrm{Ne}$ reocystis luetkeana along the coast of Washington State, USA; however, currents in their study were much stronger (ranging from 0.15 to $1.4 \mathrm{~m} \mathrm{~s}^{-1}$ ) than those measured during our study (maximum speed: $0.18 \mathrm{~m} \mathrm{~s}^{-1}$ ). Because we found that the biomass of a site is more strongly correlated to surface canopy area than mean biomass density, the potential exists for tides and currents to significantly affect estimates of biomass obtained from remote sensing. While we did not find that tides and currents introduced a major bias in our study area, they likely will have a larger effect for regions characterized by stronger currents and large tidal ranges. In addition, tides and currents may influence other species of canopy-forming kelp (such as $N$. luetkeana) differently. These factors must be taken into account if the methods developed in this paper are to be applied to other regions.

\section{Spatial correlation and variability}

Our multiscale investigation from plot to regional scales provides a framework for understanding how detailed field measurements can be scaled up in space. We found that the size of kelp forests on the site scale plays an important role in how well plot-scale measurements represent site-scale variations: plot-scale measurements of biomass provided a relatively good estimate of the biomass of the smaller kelp forests at Arroyo Burro and Mohawk, but not of the larger kelp forest at Arroyo Quemado (Fig. 4B). This was expected because as distance from a sampling plot increases, spatial autocorrelation decreases. Therefore, larger forests with complex internal structures will be more difficult to accurately characterize with a single plotscale measurement. Our semivariogram analysis enabled us to quantify the distance at which plot-scale measurements cease to have significance (see ranges in Table 2). In the alongshore direction, the mean and maximum ranges were 174 and $350 \mathrm{~m}$. The maximum alongshore length of these kelp forests was $\sim 2.5 \mathrm{~km}$; thus, characterizing larger kelp forests with plot-scale measurements will require substantial effort.

Kelp forest size is not the only control of how plotscale measurements relate to site-scale dynamics; the location of the plot within the kelp forest also plays an important role. Our analysis of pixel $(10 \mathrm{~m})$ to site $(\sim 1 \mathrm{~km})$ scale correlations (Fig. 6) indicated that forest centers are much more correlated to the dynamics of the entire forest than the edges of forests are. Taking into account both forest size and plot location illustrates why the diver plot at Arroyo Quemado was not significantly related to temporal changes at the site scale (Fig. 4B). Not only is Arroyo Quemado a larger forest $\left(\right.$ mean area $=290000 \mathrm{~m}^{2}$ ), the field sampling location was on the shoreward edge of the kelp forest, an area not well correlated to the dynamics of the entire forest (compare location of green lines in Fig. 4A to Fig. 6).

Scaling analyses can be used to maximize the efficiency of intensive field surveys. For instance, if the goal of a field sampling campaign is to characterize the dynamics of the entire kelp forest, then plots should be placed in the parts of the kelp forest (i.e. the centers) that are most persistent. Satellite imagery can be used to identify the optimal locations to place sampling plots in any kelp forest and to determine how many plots are necessary to capture site-scale changes.

Our study sites along the Santa Barbara mainland are exposed to similar oceanographic conditions, especially with regards to wave exposure. This probably explains the large degree of correlation among the larger kelp forests and the region as a whole (Table 3). The spatial consistency in temporal dynamics indicates that during our study the same forcing events were likely driving changes at scales of 1 to $60 \mathrm{~km}$. This regional homogeneity is also reflected by the fact that the CVs in biomass at site and regional scales were very similar (Fig. 9). Below the $1 \mathrm{~km}$ scale, CVs were nearly twice as high due to the large levels of within kelp forest variability and small-scale stochasticity.

Regional scale variability in giant kelp biomass for the SBC was high (CV = 83\% between 2006 and 2008), reinforcing the view that kelp forests are highly dynamic (Dayton et al. 1999, Edwards 2004). This is 
due to the frequent cycles of disturbance that affect kelp systems as well as the high growth rate of giant kelp. Because primary production by giant kelp is also highly dynamic, our work has important implications for understanding regional dynamics in net primary production (NPP) by Macrocystis pyrifera. Reed et al. (2008) found that kelp biomass present at the beginning of the growing season explained $63 \%$ of the interannual variation observed in NPP by giant kelp for the same region explored here. This result enables the local and regional dynamics of giant kelp NPP to be examined by satellite-derived estimates of biomass using imagery collected at the start of the growing season. Furthermore, because the summer biomass of giant kelp is a good predictor of annual NPP for that year (Reed et al. 2009), satellite imagery obtained in the summer can be used to estimate actual values of annual NPP by $M$. pyrifera. When coupled to data on other environmental variables (e.g. temperature, nutrients, wave energy, currents), satellite-derived estimates of giant kelp biomass offer a promising means of exploring patterns and controls of giant kelp NPP across a wide range of spatial and temporal scales.

SPOT and other similar sensors (e.g. LANDSAT) continue to provide essentially global coverage of high-resolution satellite imagery at ecologically useful timescales (i.e. LANDSAT revisits each part of the globe every $16 \mathrm{~d}$ ). Time series data obtained from these types of sensors are becoming increasingly available at little to no cost. Results from studies like ours demonstrate the utility of such data for examining a wide range of ecological patterns and processes over increasingly long time scales. Future studies that integrate satellite data with in situ measurements provide a means of calibrating remote sensing data to ecologically meaningful variables as well as the potential for obtaining much needed insight into the mechanisms producing local and regional scale patterns.

Acknowledgements. We acknowledge the support of the NASA Interdisciplinary Science program and the National Science Foundation's support of the Santa Barbara Coastal Long-Term Ecological Research site. K.C. was supported by the NASA Earth System Science fellowship program. D. Glantz kindly provided access to ISP Alginates, Inc., historical records of giant kelp abundance. Thanks to K. G. Fairbarn for image processing assistance. SPOT imagery OCNES 2008, distributed by Terra Image USA, LLC and SPOT IMAGE.

\section{LITERATURE CITED}

Augenstein EW, Stow DA, Hope AS (1991) Evaluation of SPOT HRV-XS data for kelp resource inventories. Photogramm Eng Remote Sens 57:501-509

Britton-Simmons K, Eckman JE, Duggins DO (2008) Effect of tidal currents and tidal stage on estimates of bed size in the kelp Nereocystis luetkeana. Mar Ecol Prog Ser 355: 95-105
Carpenter SR (1998) The need for large-scale experiments to assess and predict the response of ecosystems to perturbation. In: Pace ML, Groffman PM (eds) Successes, limitations, and frontiers in ecosystem science. Springer, New York, NY, p 287-312

Chavez PS Jr (1988) An improved dark-object subtraction technique for atmospheric scattering correction of multispectral data. Remote Sens Environ 24:459-479

Chavez PS Jr (1989) Radiometric calibration of LANDSAT thematic mapper multispectral images. Photogramm Eng Remote Sens 55:1285-1294

Chavez PS Jr (1996) Image-based atmospheric corrections revisited and improved. Photogramm Eng Remote Sens 62:1025-1036

Clark RN, Swayze GA, Wise R, Livo KE, Hoefen TM, Kokaly RF, Sutley SJ (2003) USGS Digital Spectral Library splib05a. US Geological Survey, Open File Report 03-395. USGS, Denver, CO

Dayton PK, Tegner MJ (1989) Bottoms beneath troubled waters: benthic impacts of the 1982-1984 El Niño in the temperate zone. In: Glynn PW (ed) Global ecological consequences of the 1982-83 El Niño-Southern Oscillation. Elsevier Oceanographic Ser No. 52, Elsevier, Amsterdam, p 433-472

Dayton PK, Tegner MJ, Edwards PB, Riser KL (1999) Temporal and spatial scales of kelp demography: the role of oceanographic climate. Ecol Monogr 69:219-250

Deutsch CV, Journel AG (1998) GSLIB geostatistical software library and user's guide. Oxford University Press, New York, NY

> Deysher LE (1993) Evaluation of remote sensing techniques for monitoring giant kelp populations. Hydrobiologia 260-261:307-312

Dugan JE, Hubbard DM, Mccrary MD, Pierson MO (2003) The response of macrofauna communities and shorebirds to macrophyte wrack subsidies on exposed sandy beaches of southern California. Estuar Coast Shelf Sci 58:25-40

Edwards MS (2004) Estimating scale-dependency in disturbance impacts: El Ninos and giant kelp forests in the northeast Pacific. Oecologia 138:436-447

> Edwards MS, Estes JA (2006) Catastrophe, recovery and range limitation in NE Pacific kelp forests: a large-scale perspective. Mar Ecol Prog Ser 320:79-87

Foster MS (1990) Organization of macroalgal assemblages in the Northeast Pacific: the assumption of homogeneity and the illusion of generality. Hydrobiologia 192:21-33

Foster MS, Schiel DR (1985) Ecology of giant kelp forests in California: a community profile. US Fish Wildl Serv Biol Rep 85(7.2)

Fowler-Walker MJ, Connell SD (2002) Opposing states of subtidal habitat across temperate Australia: consistency and predictability in kelp canopy-benthic associations. Mar Ecol Prog Ser 240:49-56

Graham MH, Vasquez JA, Buschmann AH (2007) Global ecology of the giant kelp Macrocystis: from ecotypes to ecosystems. Oceanogr Mar Biol Annu Rev 45:39-88

Harrold C, Light K, Lisin S (1998) Organic enrichment of submarine-canyon and continental-shelf benthic communities by macroalgal drift imported from nearshore kelp forests. Limnol Oceanogr 43:669-678

Jensen JR, Estes JE, Tinney L (1980) Remote sensing techniques for kelp surveys. Photogramm Eng Remote Sens 46:743-755

Levin SA (1992) The problem of pattern and scale in ecology: the Robert H. MacArthur award lecture. Ecology 73: 1943-1967

Levin SA (2000) Multiple scales and the maintenance of bio- 
diversity. Ecosystems 3:498-506

Mann KH (1973) Seaweeds: their productivity and strategy for growth. Science 182:975-981

McPhee-Shaw EE, Siegel DA, Washburn L, Brzezinski MA, Jones JL, Leydecker A, Melack J (2007) Mechanisms for nutrient delivery to the inner shelf: observations from the Santa Barbara Channel. Limnol Oceanogr 52:1748-1766

Paruelo JM, Epstein HE, Lauenroth WK, Burke IC (1997) ANPP estimates from NDVI for the Central Grassland Region of the United States. Ecology 78:953-958

Polis GA, Hurd SD (1996) Linking marine and terrestrial food webs: Allochthonous input from the ocean supports high secondary productivity on small islands and coastal land communities. Am Nat 147:396-423

Rassweiler A, Arkema KK, Reed DC, Zimmerman RC, Brzezinski MA (2008) Net primary production, growth, and standing crop of Macrocystis pyrifera in southern California. Ecology 89:2068

Reed DC, Brzezinski MA (2009) Kelp forests. In: Laffoley DG, Grimsditch G (eds) The management of natural coastal carbon sinks. IUCN, Gland, p 30-37

Reed DC, Kinlan BP, Raimondi PT, Washburn L, Gaylord B, Drake PT (2006) A metapopulation perspective on patch dynamics and connectivity of giant kelp. In: Kritzer JP, Sale PF (eds) Marine metapopulations. Academic Press, San Diego, CA, p 353-386

Reed DC, Rassweiler A, Arkema KK (2008) Biomass rather than growth rate determines variation in net primary production by giant kelp. Ecology 89:2493-2505

Reed DC, Rassweiler A, Arkema KK (2009) Density derived estimates of standing crop and net primary production in the giant kelp Macrocystis pyrifera. Mar Biol 156: 2077-2083

Ricotta C, Avena G, De Palma A (1999) Mapping and monitor-

Editorial responsibility: Matthias Seaman,

Oldendorf/Luhe, Germany ing net primary productivity with AVHRR NDVI timeseries: statistical equivalence of cumulative vegetation indices. ISPRS J Photogramm Remote Sens 54:325-331

Schneider DC (2001) The rise of the concept of scale in ecology. Bioscience 51:545-553

> Stekoll MS, Deysher LE, Hess M (2006) A remote sensing approach to estimating harvestable kelp biomass. J Appl Phycol 18:323-334

Steneck RS, Graham MH, Bourque BJ, Corbett D, Erlandson JM, Estes JA, Tegner MJ (2002) Kelp forest ecosystems: biodiversity, stability, resilience and future. Environ Conserv 29:436-459

Su H, Karna D, Fraim E, Fitzgerald M and others (2006) Evaluation of eelgrass beds mapping using a high-resolution airborne multispectral scanner. Photogramm Eng Remote Sens 72:789-797

Tucker CJ (1979) Red and photographic infrared linear combinations for monitoring vegetation. Remote Sens Environ 8:127-150

Tucker CJ, Vanpraet CL, Sharman MJ, Vanittersum G (1985) Satellite remote sensing of total herbaceous biomass production in the Senegalese Sahel: 1980-1984. Remote Sens Environ 17:233-249

Veisze P, Kilgore A, Lampinen M (2001) Building a California kelp knowledge database using GIS. Proc 2001 ESRI Education User Conf, ESRI paper 900. ESRI, San Diego, CA

> Vetter EW, Dayton PK (1999) Organic enrichment by macrophyte detritus, and abundance patterns of megafaunal populations in submarine canyons. Mar Ecol Prog Ser 186:137-148

Yang D, Yang C (2009) Detection of seagrass distribution changes from 1991 to 2006 in Xincun Bay, Hainan, with satellite remote sensing. Sensors 9:830-844

Submitted: August 18, 2009; Accepted: December 21, 2009 Proofs received from author(s): March 11, 2010 